\title{
Effect of oil and oil with graphite on tribological properties of glass filled PTFE polymer composites
}

\author{
Y R KHARDE* and K V SAISRINADH \\ Department of Mechanical Engineering, National Institute of Technology, Warangal, India
}

MS received 3 February 2010; revised 2 April 2010

\begin{abstract}
Present work deals with the experimental investigation of tribological properties of GF-filled polymer composites considering three velocities, i.e. $0.5,1$ and $2.0 \mathrm{~m} / \mathrm{s}$ and loads ranging from $15.7 \mathrm{~N}$ to 45.13 $\mathrm{N}$ keeping rest of the parameters constant. The test has been carried out for three materials, PTFE + 15\% GF, PTFE + $25 \%$ GF and PTFE + 35\% GF in wet (oil) and adding additive as graphite (5\% wt) in oil. SAE 20W40 oil is used for the test. Friction and wear tests of PTFE composite against a counter surface of EN8 with surface finish of $0.56 \mu \mathrm{m}$ are carried out at ambient conditions using pin-on-disc tribometre (TR-20), Ducom make, Bangalore. The results are tabulated and graphs are plotted. It has been found that load and wet conditions have significant effect on coefficient of friction and specific wear rate of the materials. Where as sliding velocity also plays little role in wear mechanism of the material. It is concluded from the experimental study that the specific wear rate in wet condition as well as by adding additives in lubricating oil with $5 \%$ (by wt.) has been declined. Also the specific wear rate decreases with normal load and sliding velocity. Wear of PTFE + GF composite decreases with increase in glass percentage. Microscopic analysis of pin and disc surface is made with optical microscope. The mathematical models has been developed by using regression analysis and found to be valid for the above tested parameters.
\end{abstract}

Keywords. PMC's; coefficient friction; wear; glass fibre; specific wear rate; graphite additive.

\section{Introduction}

Polymers and polymer composites are steadily gaining ground over metals in the field of engineering applications in tribology. Laboratory wear tests are carried out by various researchers under ambient temperatures with no lubricant as well as in distilled water. Wide range of work has been carried out regarding the influence of test conditions, contact geometry, environment and counter face materials on the friction and wear behaviour of polymers. Influence of test speed and load values on the friction and wear behaviour of pure polytetrafluoroethylene (PTFE), glass fibre reinforced (GF) and bronze and carbon filled PTFE polymers have showed that, PTFE + $17 \%$ GF exhibited best wear performance and is a very good tribo-material between materials used in their study (Unal et al 2004). The friction coefficient of pure PTFE and its composites decreases with increase in applied load. Pure PTFE is characterized by high wear because of its small mechanical properties. For the specific range of load and speed explored in this study, the load has stronger effect on the wear behaviour of PTFE

*Author for correspondence

(kharde999@gmail.com; kvsaisrinadh@yahoo.com) and its composites than the sliding velocity (Unal et al 2006). Chemical bond formation which enhances the adherence of the transfer film is reported to occur at the polymer-metal interface by various researchers (Klaasa et al 2005). Hard particulate fillers consisting of ceramic or metal particles and fibre fillers made of glass are being used these days to dramatically improve the mechanical properties such as wear resistance, even up to three orders of magnitude (Gregory et al 2003).

As the particle sizes of the filler material used in PTFE are diminishing down to nano-scale significant improvements of the wear resistance of polymers were achieved at very low nano-filler content (Klaus Friedrich et al 2005). The friction coefficient decreases with temperature down to $77^{\circ} \mathrm{K}$, but did not follow a linear evolution further down to extreme low temperatures (Theiler et al 2002).

Transfer films are formed in sliding between polymer and polymer as well as polymer and metal. Wear occurs by the loss of material before transfer to the counterface and the loss of transfer film by peeling from the counterface (Shyam Bahadur 2000). The wear life of the transfer film of PTFE is short because PTFE cannot form durable transfer film on the steel counterface. PTFE is to form big flakes and left the contacting region during the friction process (Yunxia Wang and Fengyuan Yan 2006). Friction 
and wear properties of polyamide 66 (PA66), polyphenylene sulphide (PPS) and Polytetrafluoroethylene (PTFE) are sliding against themselves under dry sliding and oil-lubricated conditions by using a pin-on-disc tribometer. Experimental results showed that friction properties of these sliding combinations could be greatly improved by oil lubrication (Bin-Bin Jia et al 2007). The friction and wear behaviours of bearings are affected by speed, load, temperature and working time (Erol Feyzullahoglu and Zehra Saffak 2008). The disc wear was more severe as the difference in hardness between pin and disc increases. They observed wear mechanisms in the SEM are micro-grooving or micro-cutting, adhesion and micro-delimination or micro-flaking (Bressana et al 2008).

Influence of temperature with three types of PTFE (pure and filled with glass fibre and carbon-graphite) against grey cast iron and showed the increase of temperature reduces wear and friction coefficient except for PTFE. The wear particles have rather soft shape attributes (Kowandya et al 2008). Sliding condition such as environmental temperature, applied load, sliding speed and lubricating condition significantly affect the friction and wear performance of the unfilled and filled hybrid glass and PTFE fabric composite (Feng-hua Sua et al 2008). Wear rates and friction stability were affected by the relative amounts of solid lubricants in the friction composites. Addition of graphite with low content of h-BN can stabilize tribological properties of $\mathrm{Cu}$-based polymer friction composites, graphite can form relatively compact tribo-films than that of h-BN in the wear process. These compact solid lubricant-rich films are helpful to improve wear resistance of $\mathrm{Cu}$-based friction composites (Baiming Chen et al 2008). Nano-particles including $\mathrm{CuO}, \mathrm{TiO}_{2}$, and nano-diamond used as additives in lubricating oils exhibit good friction reduction and anti-wear behaviour (Wu et al 2007).

The interaction between liquid paraffin and the PTFE composites especially the absorption of liquid paraffin into the surface layers of the PTFE composites creates some cracks on the worn surfaces of the PTFE composites. This would lead to the deterioration of the friction and wear properties of the PTFE composites under higher loads in liquid paraffin lubrication (Yuji Yamamoto and Masaaki Hashimoto 2004). PEEK reinforced with glass fibre was little improved in friction and wear characteristics, since both PEEK and glass fibre has poor resistance to wear in water. In contrast, the addition of carbon fibre to PEEK made the friction and wear characteristics excellent (Zhao-Zhu Zhang et al 1997).

As many researchers have investigated the triboproperties of the glass filled materials in dry and wet conditions, after going through the research paper it is observed that there is scope in carrying out the experimentation in the presence of graphite as an additive in oil. In this research paper, an effort has been made to investigate the tribo- logical properties of the PTFE-based glass filled composites. The objective behind this work is to study the effect of load, velocity, lubricant, lubricant with graphite additive and also an attempt has been made to find out the effect of filler content on tribological properties of these composites.

\section{Materials and methods}

\subsection{Mechanical properties}

Table 1 shows the mechanical properties of the material used for the experimental investigation of tribological properties. Durometer was used to measure the hardness of the composites. It was observed that as the percentage of filler material increases the hardness also increases and there is increase in the density of the materials.

\subsection{Material manufacturing}

PTFE composites were manufactured by means of compression sintering. The material was purchased from Perfect Packaging Pvt. Ltd., Pune. The test pins were prepared by using $\mathrm{CNC}$ centre lathe, grinding and then polishing the top and bottom surfaces.

\subsection{Testing facilities}

Figure 1(a) shows the pin-on-disc type tribometer (TR20) and figure 1(b) shows the test specimens of size $\phi$ $10 \mathrm{~mm}$ diameter and $25 \mathrm{~mm}$ length. Specimen pins for the testing are made from PTFE composite rods. The surfaces are cleaned by acetone liquid before and after the test. Separate pins were used for each test. Each test was repeated for three times and average value of the mass loss measured in $\mathrm{mm}^{3}$. All the tests were performed under relative humidity $\mathrm{RH}=55-60 \%$, and ambient temperature condition of $27-29^{\circ} \mathrm{C}$ for $72 \mathrm{~min}$. Figure 1(c) shows the counter-surface made up of EN8 material having surface hardness $72 \mathrm{HRC}$ and surface roughness $R_{\mathrm{a}}=0.56 \mu \mathrm{m}$.

\subsection{Testing conditions}

Table 2 shows the parameters selected for the test. Firstly, the tests were carried out in wet condition by using SAE $20 \mathrm{~W} 40$ oil and then $5 \%$ by weight graphite as an additive was added into oil. Graphite powder with particle size ranging $10-20 \mu \mathrm{m}$ was mixed with oil and the test was carried out. Sufficient amount of oil was maintained during the test for oil to remain continuously in contact with the specimen pin and counter surface. 
Table 1. Mechanical properties of materials.

\begin{tabular}{lcccc}
\hline S1. no. & Material designation & Material & Density $(\mathrm{g} / \mathrm{cc})$ & Shore hardness $(D)$ \\
\hline 1 & $\mathrm{~B}$ & PTFE + 15\% GF & $2 \cdot 13$ & 59 \\
2 & $\mathrm{C}$ & PTFE + 25\% GF & $2 \cdot 18$ & 61 \\
3 & $\mathrm{D}$ & PTFE + 35\% GF & $2 \cdot 52$ & 64 \\
\hline
\end{tabular}
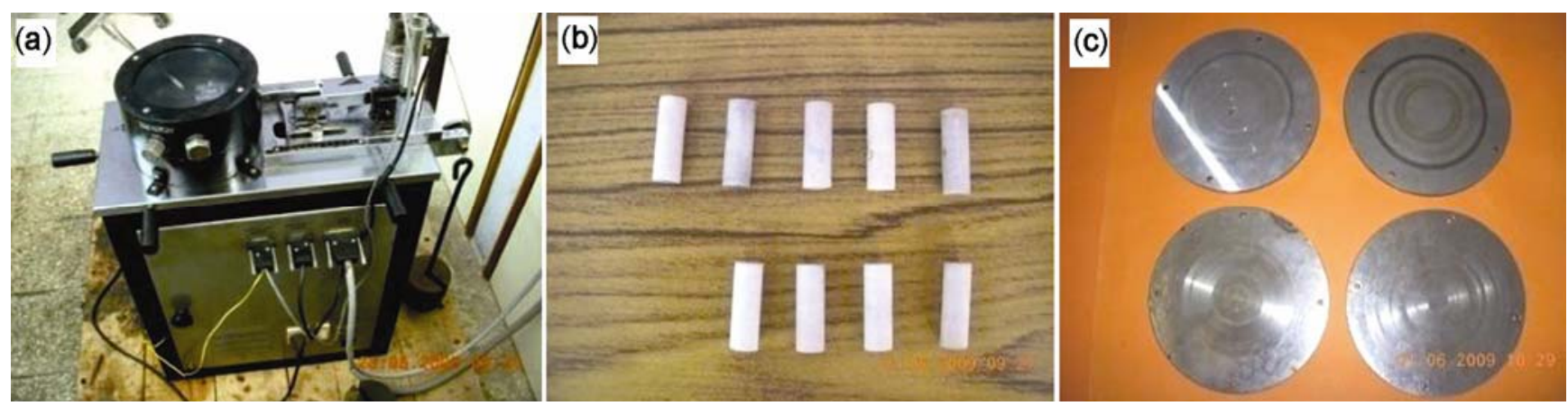

Figure 1. (a) Tribometer (TR-20), (b) specimens pins and (c) and counter surface (EN8) discs.
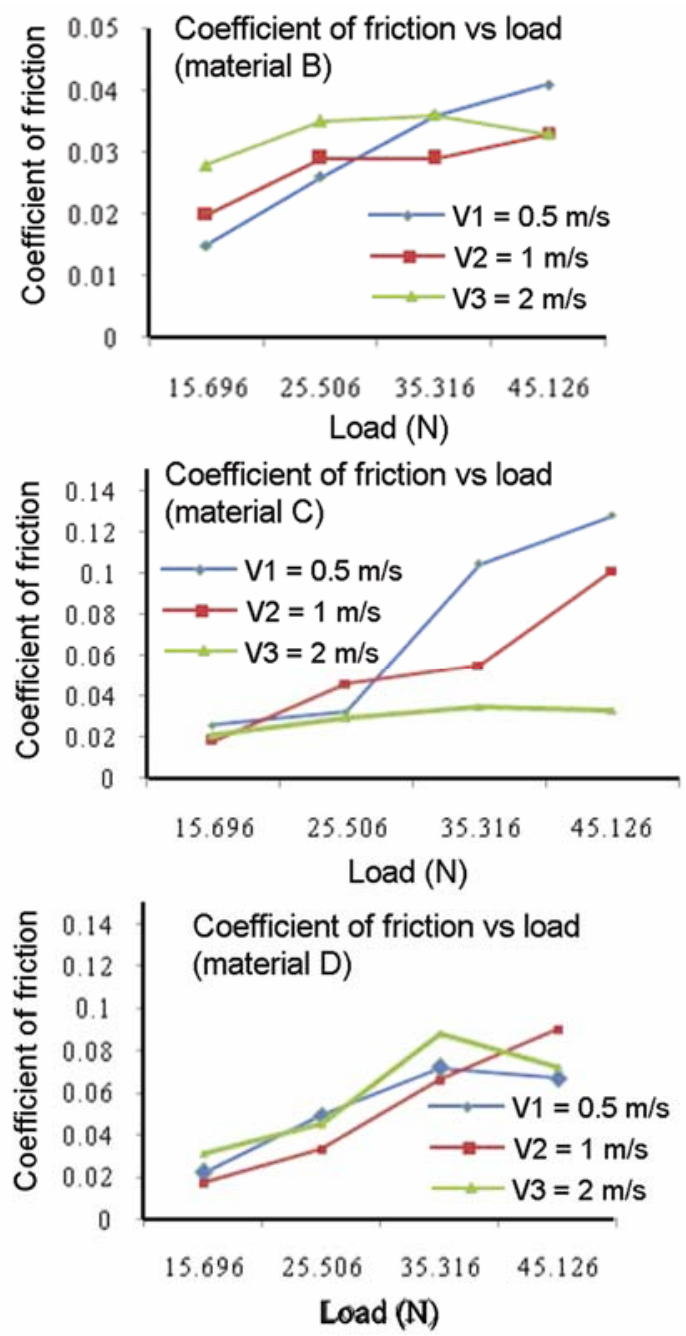

Figure 2. Coefficient of friction with load for materials B, C and $\mathrm{D}$ in oil lubrication.

\section{Results and discussions for oil lubrication}

\subsection{Effect of load on coefficient of friction at various velocities}

Figures 2(a)-(c) show the variation of the coefficient of friction with load at constant velocities for all the materials. From the graphs it can be concluded that at lower speed the coefficient of friction increases with increase in load but as the applied load is increased beyond $35 \mathrm{~N}$, coefficient of friction remains constant or it may decrease with increase in applied load. The average range of coefficient of friction for the GF-based PTFE composites for oil lubrication condition is about 0.015 to 0.1 which is far lesser than in dry condition. Even after $45 \cdot 13 \mathrm{~N}$ load for all the materials, the COF almost remains constant. The stabilization of the COF at higher loads and at higher velocity would be due to the filling up of the micro asperities by filler and matrix material and the surface appearing very smooth. At constant speed the temperature at the frictional surface increases with load while viscosity decreases. The variation of viscosity with temperature and load shows variations in coefficient of friction. Here it has been found that the coefficient of friction increases and then remains constant.

\subsection{Effect of load on specific wear rate at various velocities in oil lubrication}

Figures 3(a)-(c) show the variation of specific wear rate with applied load at different velocities under oil lubrication. From the figures it is clear that for PTFE $+\mathrm{GF}$ composites for a given load range, specific wear rate 
Table 2. Parameters used for test.

\begin{tabular}{lll}
\hline S1. no. & \multicolumn{1}{c}{ Parameters } & \multicolumn{1}{c}{ Values } \\
\hline 1 & Velocity $(\mathrm{m} / \mathrm{s})$ & $V_{1}=0.5 \mathrm{~m} / \mathrm{s}, V_{2}=1.0 \mathrm{~m} / \mathrm{s}, V_{3}=2 \cdot 0 \mathrm{~m} / \mathrm{s}$ \\
2 & Load (N) & $P_{1}=15 \cdot 7 \mathrm{~N}, P_{2}=25.5 \mathrm{~N}, P_{3}=35 \cdot 3 \mathrm{~N}, P_{4}=45 \cdot 1 \mathrm{~N}$ \\
4 & Contact pressure (MPa) & $0 \cdot 2 \mathrm{MPa}, 0 \cdot 325 \mathrm{MPa}, 0.45 \mathrm{MPa}, 0.57 \mathrm{MPa}$ \\
3 & Conditions & Wet (SAE20W40 Oil), wet $+5 \%$ graphite \\
\hline
\end{tabular}
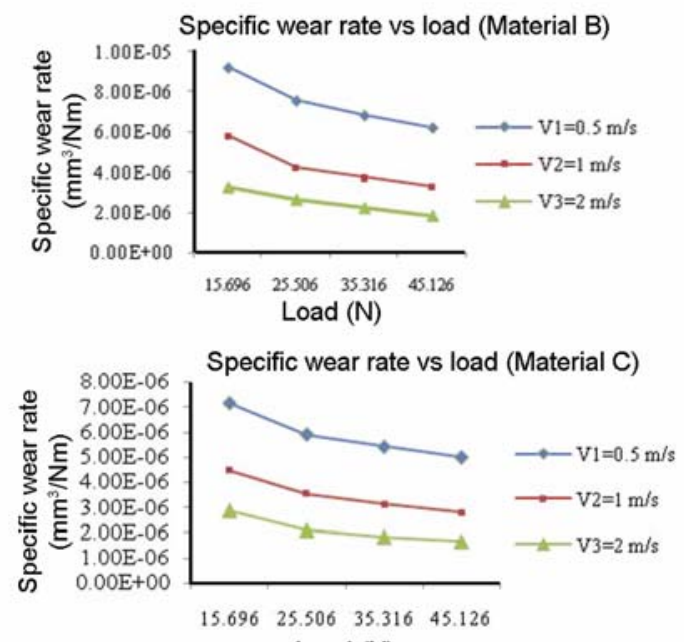

Load $(\mathrm{N})$

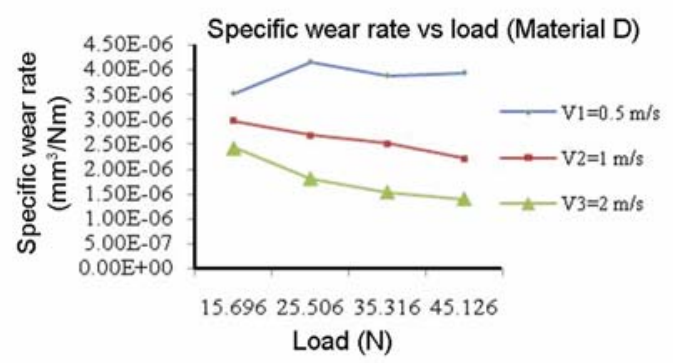

Figure 3. Specific wear rate with load for B, C and D in oil lubrication.

decreases with increase in applied load. This is the trend observed for all the materials. Hence these composites have good wear properties at higher loads. At higher loads and velocities there may be formation of micro thin layer of transfer film along with the filler material which remains on the counter surface and does not break in oil lubrication condition. With increase in sliding speed a layer of lubricating oil film can be more easily formed on frictional surface, thus the lubrication condition of the frictional surface can be greatly improved leading to decrease in wear rate. As the specific wear rate is lower at higher loads the material offers high resistance to wear (Zhao-Zhu Zhang et al 1997).

\subsection{Comparison of specific wear rate with load for} materials $B, C$ and $D$ in oil lubrication at various velocities

Figures 4(a)-(c) show the wear behaviour of materials B, $\mathrm{C}$ and $\mathrm{D}$ on the basis of specific wear rate at various velocities. From the figure it is clear that specific wear rate of PTFE material D is less as compared to materials $\mathrm{B}$ and $\mathrm{C}$. Therefore material $\mathrm{D}$ is the best material than $\mathrm{B}$ and $\mathrm{C}$ under oil lubrication. The normal range of specific wear rate at $2 \mathrm{~m} / \mathrm{s}$ is about $1.4 \times 10^{-6} \mathrm{~mm}^{3} / \mathrm{Nm}$ to $3.25 \times$ $10^{-6} \mathrm{~mm}^{3} / \mathrm{Nm}$ which is less than the specific wear rate in dry condition. That is, there is high resistance to wear at high velocity and higher load of material with $35 \%$ GF. This may be due to the strong adhesive film of filler and the matrix material on the counter surface. These results are in good agreement with the published results (Baiming Chen et al 2008).

\section{Results and discussions for oil $+5 \%$ graphite lubrication}

\subsection{Effect of load on coefficient of friction at various velocities}

Figures 5(a)-(c) show the variation of the coefficient of friction with load at constant velocities. From the graphs it is clear that, at lower velocity the coefficient of friction increases with increase in load but as the applied load increases beyond $35 \mathrm{~N}$ coefficient of friction remains constant or it may decrease with increase in applied load. At $2 \mathrm{~m} / \mathrm{s}$ it gives good friction properties. Also for material $\mathrm{B}$ frictional coefficient is about 0.12 to 0.25 which is more than $\mathrm{C}$ and $\mathrm{D}$. Hence in oil and graphite lubrication, material $\mathrm{B}$ has poor friction properties. Lower value of COF has been observed for the material with $35 \% \mathrm{GF}$.

\subsection{Effect of load on specific wear rate at various velocities in oil with 5\% graphite lubrication}

Figures 6(a) and (b) describe the variation of specific wear rate with applied load at different velocities under oil with 5\% wt. graphite as an additive in oil. From the figures it is clear that for PTFE with GF composites for a given load range specific wear rate decreases with increase in applied load in almost all the cases. At higher load and speed it shows less specific wear rate. Hence these composites have good wear properties at higher loads. Graphite film is capable to bear the high load than the oil lubrication, so PTFE composites show good wear properties under this lubricating conditions. Graphite can form relatively compact tribo-films. These compact solid lubricant-rich films are helpful to improve wear resistance 
Table 3. Treatment combinations and experimental results.

\begin{tabular}{cccccc}
\hline Trial no & $\begin{array}{c}\text { Pressure } \\
P(\mathrm{MPa})\end{array}$ & $\begin{array}{c}\text { Sliding } \\
\text { velocity } v(\mathrm{~m} / \mathrm{s})\end{array}$ & $\begin{array}{c}\text { Glass fibre } \\
g(\mathrm{~m} / \mathrm{s})\end{array}$ & $\begin{array}{c}\text { Wear wet } \\
\left(\mathrm{mm}^{3}\right)\end{array}$ & $\begin{array}{c}\text { Wear wet }+5 \% \\
\text { GRF }\left(\mathrm{mm}^{3}\right)\end{array}$ \\
\hline 1 & -1 & -1 & -1 & $3 \cdot 97$ & $5 \cdot 31$ \\
2 & 1 & -1 & -1 & $6 \cdot 63$ & $8 \cdot 06$ \\
3 & -1 & 1 & -1 & $5 \cdot 59$ & $8 \cdot 98$ \\
4 & 1 & 1 & -1 & $8 \cdot 59$ & $6 \cdot 49$ \\
5 & -1 & -1 & 1 & $1 \cdot 52$ & $6 \cdot 01$ \\
6 & 1 & -1 & 1 & $3 \cdot 77$ & $4 \cdot 03$ \\
7 & -1 & 1 & 1 & $4 \cdot 19$ & $1 \cdot 64$ \\
8 & 1 & 1 & 1 & $5 \cdot 94$ & $2 \cdot 64$ \\
9 & 0 & 0 & 0 & $4 \cdot 97$ & $4 \cdot 27$ \\
10 & 0 & 0 & 0 & $5 \cdot 87$ & $4 \cdot 28$ \\
11 & 0 & 0 & 0 & $4 \cdot 67$ & $4 \cdot 22$ \\
12 & 0 & 0 & 0 & $5 \cdot 64$ & $4 \cdot 31$ \\
\hline
\end{tabular}
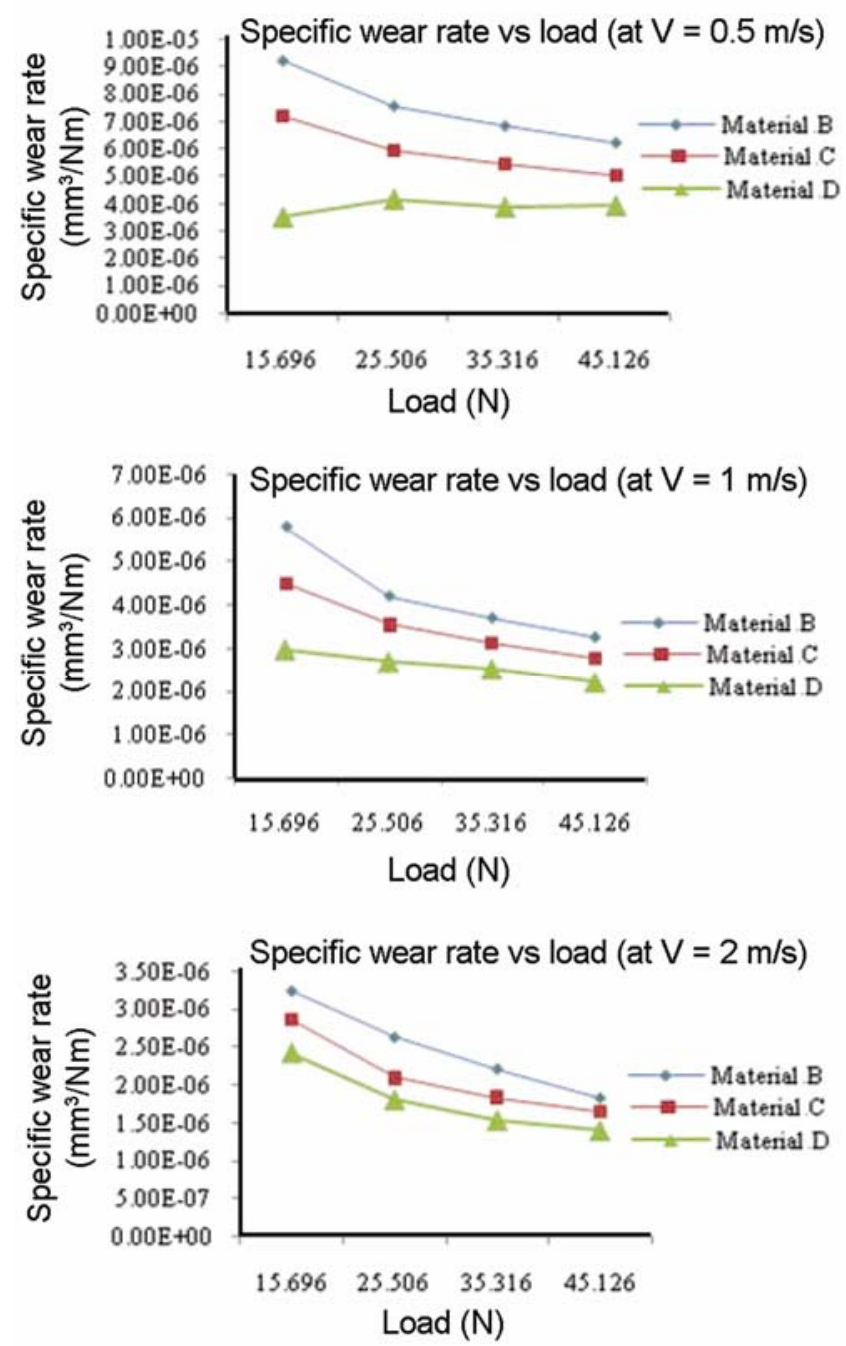

Figure 4. Specific wear rate with applied load for PTFE + GF composites in oil lubrication.

of PTFE-based friction composites (Baiming Chen et al 2008).

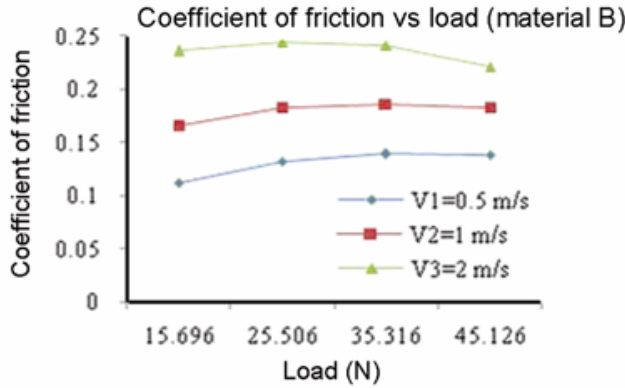

Coefficient of friction vs load (material C)

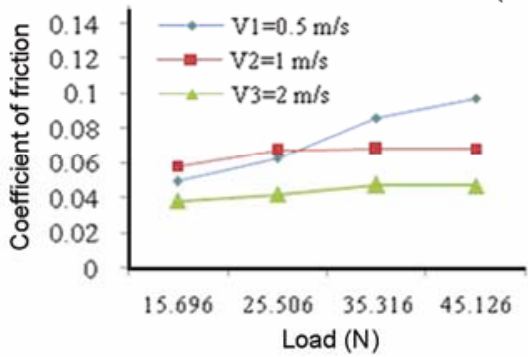

Coefficient of friction vs load (material D)

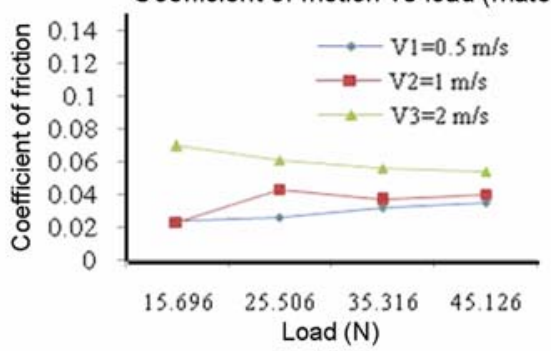

Figure 5. Effect of applied load on coefficient of friction of PTFE + GF composites under oil $+5 \%$ graphite lubrication

4.3 Comparison of specific wear rate with load for materials $B, C$ and $D$ in oil with 5\% graphite lubrication at various velocities

From figures 7(a)-(c) it is clear that specific wear rate of material $\mathrm{D}$ is less as compared to materials $\mathrm{B}$ and $\mathrm{C}$. Material B shows poor wear properties under this condi- 
tion than oil lubrication; material D shows excellent wear resistance in this lubrication condition than oil lubrication. This may be due to the higher hardness of material D. Also there must be filling of the micro asperities by glass filler and matrix particles and in presence of the oil the bond between glass filler and the counter surface must be strong which does not get break at higher loads. The normal range of specific wear rate for material $D$ is about $1.2 \times 10^{-6} \mathrm{~mm}^{3} / \mathrm{Nm}$ to $3.75 \times 10^{-6} \mathrm{~mm}^{3} / \mathrm{Nm}$. The specific wear rate values for $\mathrm{C}$ and $\mathrm{D}$ are very close to one another.

\subsection{Comparison COF with load for oil and oil with 5\% graphite lubrication}

Figure 8 shows the variation of coefficient of friction with load in oil lubricated and oil with $5 \%$ graphite (additive) conditions at constant sliding velocity of $2 \mathrm{~m} / \mathrm{s}$ for all the materials. For materials $\mathrm{B}$ and $\mathrm{C}$ the minimum value of frictional coefficient is observed in oil-lubricated condition and maximum value is observed in oil with graphite lubrication. Material B shows the higher frictional coefficient in oil with graphite condition than oillubricated condition. Material $\mathrm{C}$ shows almost same value of frictional coefficient in oil and oil with graphite lubricated conditions. Material $\mathrm{C}$ shows the minimum frictional coefficient in oil with graphite condition. This value of frictional coefficient obtained in oil with graphite is less. This may be due to sliding friction transferred to rolling friction in the presence of graphite micro particles in oil; also due to enhancing of the adhesion of transfer films by the presence of glass fillers

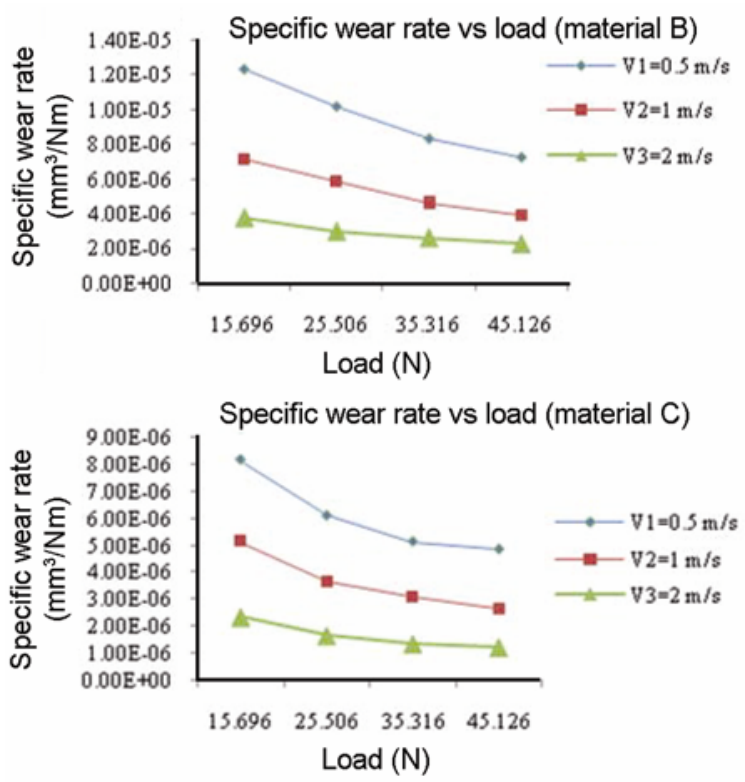

Figure 6. Specific wear rate with load on of PTFE + GF composites in oil and graphite lubrication. to the counter surface which reduces the wear and friction gets transferred to the PTFE composite and transfer film which reduces the coefficient of friction (Zhao-Zhu Zhang et al 1997).

\subsection{Comparison specific wear rate with load for oil and} oil with 5\% graphite lubrication

Figure 9 shows the effect of lubricating condition on specific wear rate of materials $\mathrm{B}, \mathrm{C}$ and $\mathrm{D}$ at constant sliding velocity of $2 \mathrm{~m} / \mathrm{s}$. From the figure it is clear that, for material $\mathrm{C}$ the minimum value of specific wear rate is observed in oil lubrication condition and also in oil with graphite lubrication. Materials C and D show minimum specific wear rate in oil with $5 \%$ graphite (additive). Therefore, C and D have better wear properties in oil with graphite lubrication than oil lubrication. Hence these materials can be used in similar lubricating conditions. The figure also shows almost constant specific wear rate with increase in load under oil with graphite lubrica-
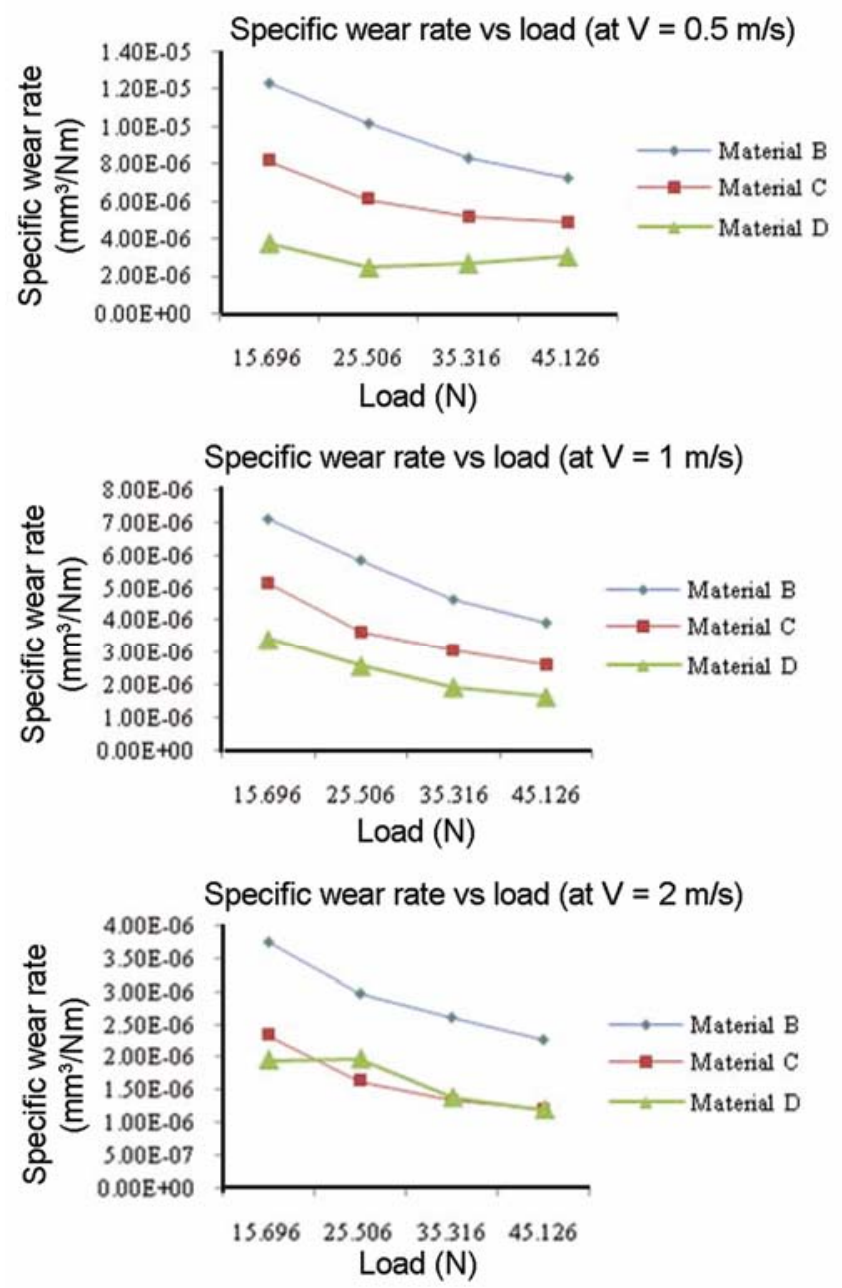

Figure 7. Specific wear rate with load for PTFE + GF composites in oil $+5 \%$ graphite lubrication. 
tion conditions; this lubricating condition gives better wear properties for PTFE with GF composites. This may be due to the presence of higher percentage of GF and of graphite micro/nano particles between pin and the disc surfaces. In oil, sliding friction must have transferred to rolling friction which reduces the wear of the PTFE with glass fibre composites. Wear reducing properties of the PTFE composites can be greatly improved by oil lubrication (Lancaster 1968).

\section{Microscopic analysis}

Figure 10(a) shows the optical microstructure of PTFE with GF fibre which shows that the glass fibres are randomly oriented in to the PTFE matrix. Figure 10(b) clearly shows pieces of glass fibre fragments scattered on the counterface. Optical microscopy indicates that the mechanism of wear for glass fibre-filled PTFE is dominated by the debonding and pullout of fibres from the matrix. In microscopy broken glass fibres were clearly seen on the pin surface after the wear test. This fibre increases the wear strength of the PTFE with glass fibre composites and reduces the wear of the material.

Figures 11(a) and (b) show the optical microscopic images of pin surface for materials $\mathrm{B}$ and $\mathrm{C}$ after the wear test which has been carried out at load as $45 \cdot 1 \mathrm{~N}$ and sliding velocity of $2 \mathrm{~m} / \mathrm{s}$. From the figures it is seen that the longer

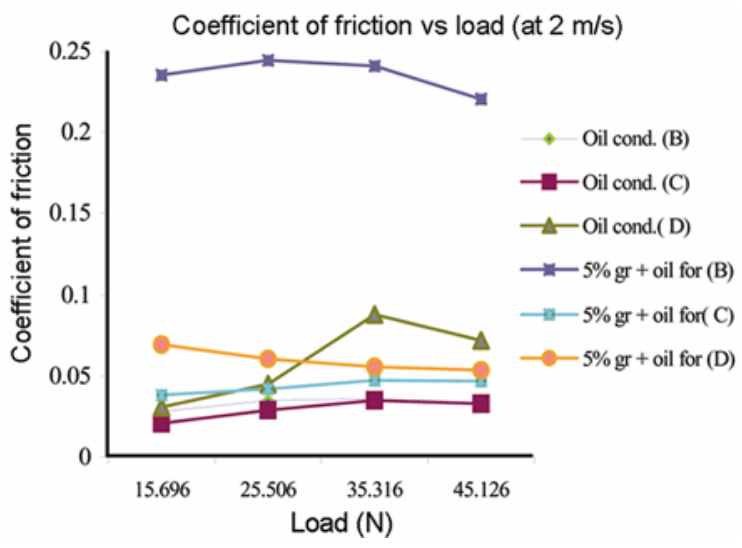

Figure 8. Coefficient of friction with load in oil and oil with $5 \%$ graphite for $\mathrm{B}, \mathrm{C}$ and $\mathrm{D}$ materials.

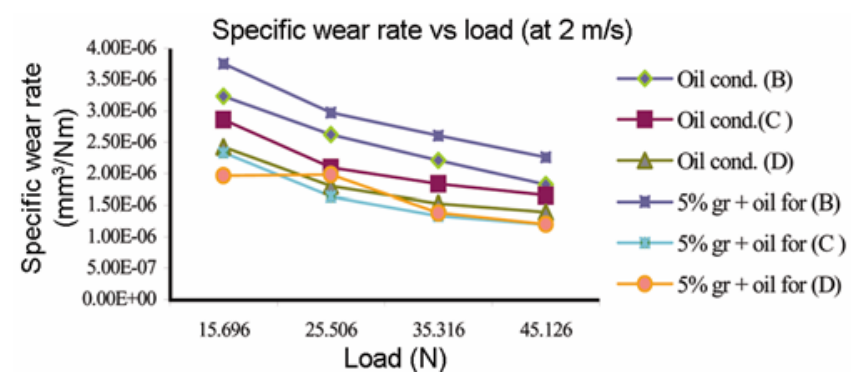

Figure 9. Comparison of materials B, C, D for specific wear rate in oil and oil with $5 \%$ graphite. fibres break into smaller fragments and spread in the form of thin layer on the pin surface during wear test between the pin and the disc. Microscopy of material $\mathrm{C}$ shows more uniform spreading of glass fibres on the pin surface, which increases the wear resistance of PTFE and GF composites.

Figures 12(a) and (b) show the optical microscopy of pin surface of $C$ and $D$ materials after the wear test which has been carried out at load of $45 \cdot 1 \mathrm{~N}$ and sliding velocity of $2 \mathrm{~m} / \mathrm{s}$. From this misconstrue it is seen that glass fibres were more uniformly distributed on the pin surface during wear test. From figures 12 (a) and (b) it is seen that wear tracks observed on the pin surface shows the abrasive wear of the PTFE composites. Hence the abrasive wear is the main wear during testing against the EN8 disc.

Figures 13(a) and (b) show that most of the valleys are filled with transfer material during wear test. These micrographs show scratch marks on the disc surface which are caused by the abrasion of the glass fragments. Microscopy indicates that the mechanism of wear for glass fibre-filled PTFE is dominated by the debonding and pull out of fibres from the PTFE matrix. The longer fibres also seen to break into smaller fragments before they pull out. The adherence of the film to the counterface is thought to be due to the mechanical interlocking of the polymer fragments into the asperity valleys of the metal counterface. During the sliding process, the asperity valleys are filled as polymer gets filled into the valleys leading to the formation of a thin layer of polymer between the composite pin and the counterface.

The glass fibres that are loosely bound to the PTFE matrix debond and pull out of the matrix. As sliding progresses, the fibres are further broken down into smaller fragments and act as a third body between the polymer composite pin and the metal surface.

\section{Design of experiment}

Factorial design used in this work is a composite one. It is more efficient than the conventional one-factor-at-atime experiments commonly employed by researchers. A design consist of 12 experiments, which are used to develop the wear model equations. Eight experiments represent a $2^{3}$ factorial design, where the eight experimental points are located at the vertices of a cube as shown in figure 14. Four experiments represent an added centrepoint to the cube, repeated four times to estimate the pure error. This method classifies and identifies the parameters to three different levels (low, centre and high). In this experimentation, 12 tests were carried out at these levels. These test values were divided in two groups of six readings each and one combined group (trial numbers 1-12) and for each group wear model equations were obtained: (i) first block of six test (trial numbers 2, 3, 5, 8, 

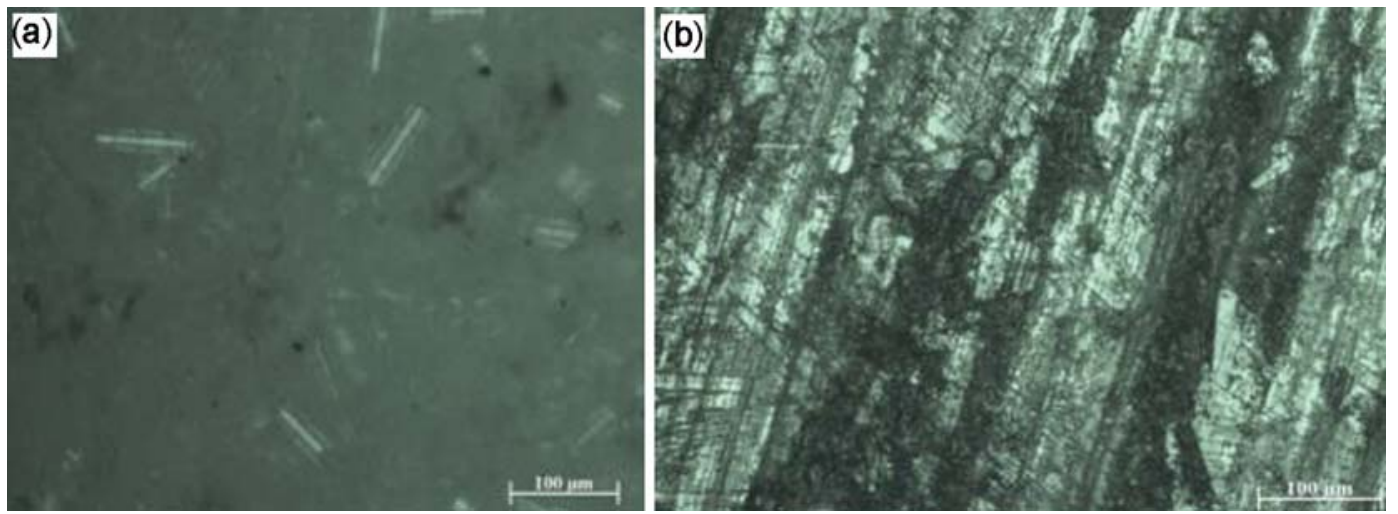

Figure 10. (a) Optical microscopy of PTFE $+35 \%$ GF before wear test $(100 \times)$; and (b) Pin surface of PTFE $+15 \%$ GF after wear test at $P=45 \cdot 1 \mathrm{~N} V=2 \mathrm{~m} / \mathrm{s}(100 \times)$.

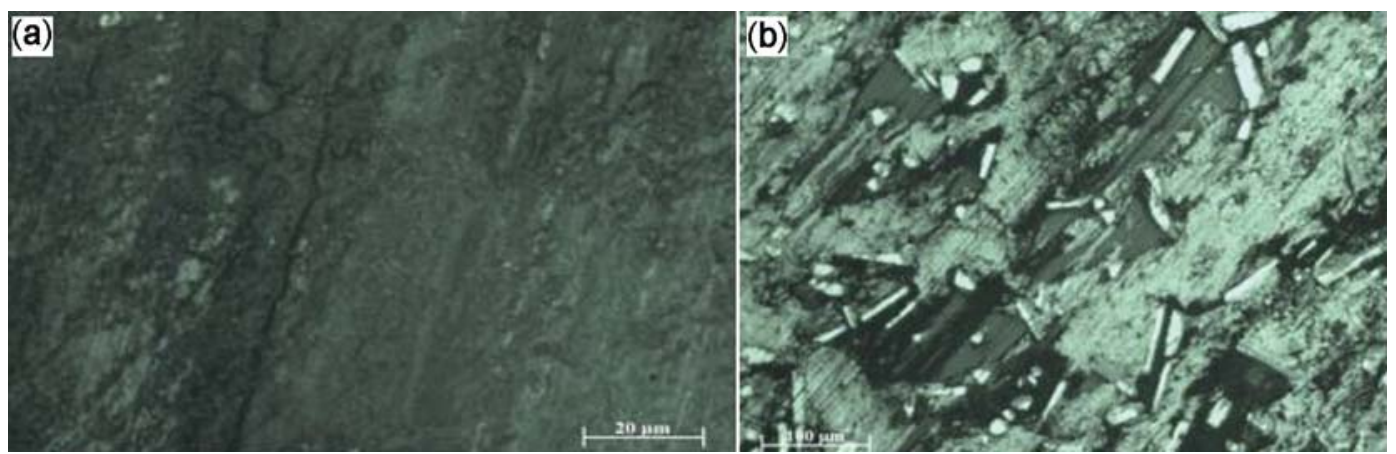

Figure 11. (a) Optical microscopy of pin surface of PTFE $+15 \%$ GF after wear test at $P=45 \cdot 1 \mathrm{~N}$ and $V=2 \mathrm{~m} / \mathrm{s}(500 \times)$; and $(\mathbf{b})$ pin surface of PTFE $+25 \%$ GF after wear test at $P=45 \cdot 1 \mathrm{~N} V=2 \mathrm{~m} / \mathrm{s}(100 \times)$.
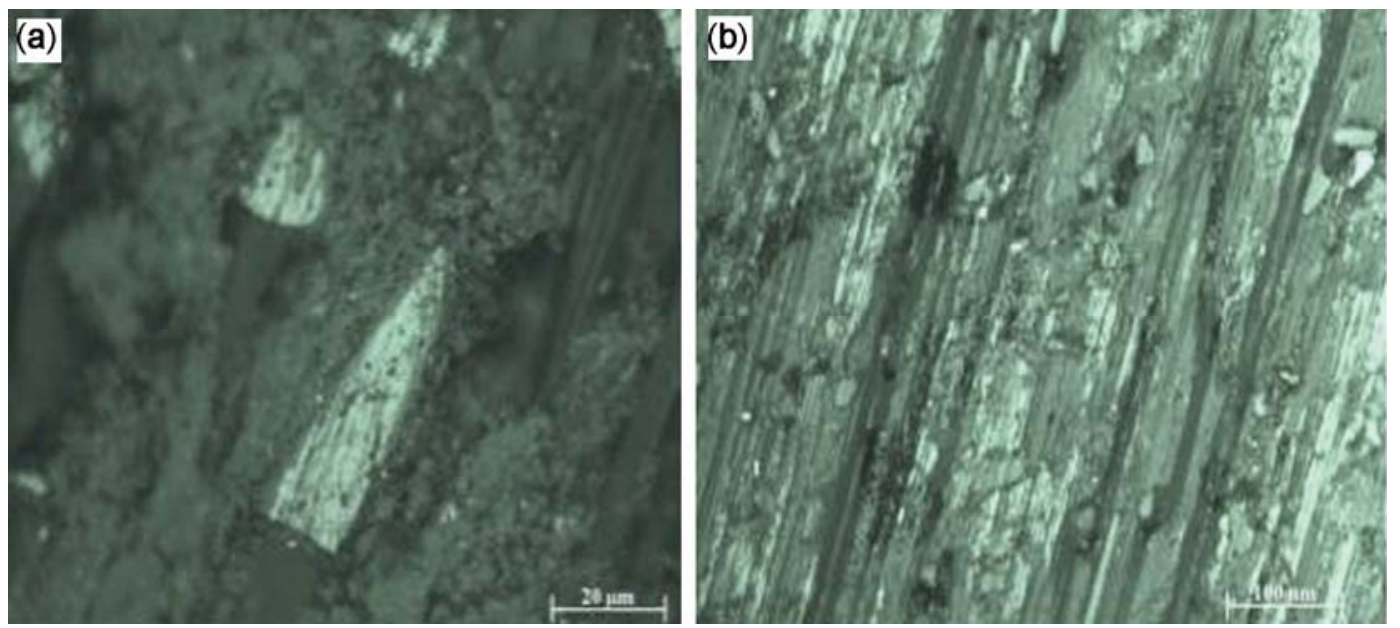

Figure 12. (a) Optical microscopy of pin surface of PTFE $+25 \% \mathrm{GF}$ after wear test at $P=45 \cdot 1 \mathrm{~N}$ and $V=2 \mathrm{~m} / \mathrm{s}(500 \times) ;(\mathbf{b})$ optical microscopy of pin surface of PTFE $+35 \% \mathrm{GF}$ after wear test at $P=45 \cdot 1 \mathrm{~N}$ $V=\mathrm{m} / \mathrm{s}(100 \times)$.

9 and 10); (ii) second block of six tests (trial numbers 1 , 4, 6, 7, 11 and 12); and (iii) combined blocks of twelve tests (trial numbers 1-12). The analysis of these blocks were carried out using analysis of variance technique (Shirsath and Ahuja 2005).

\subsection{Results of regression analysis}

Tables 4 and 5 show the results obtained by regression analysis for wet and wet with 5\% wt. of graphite as an additive in oil lubrication. Regression coefficient 

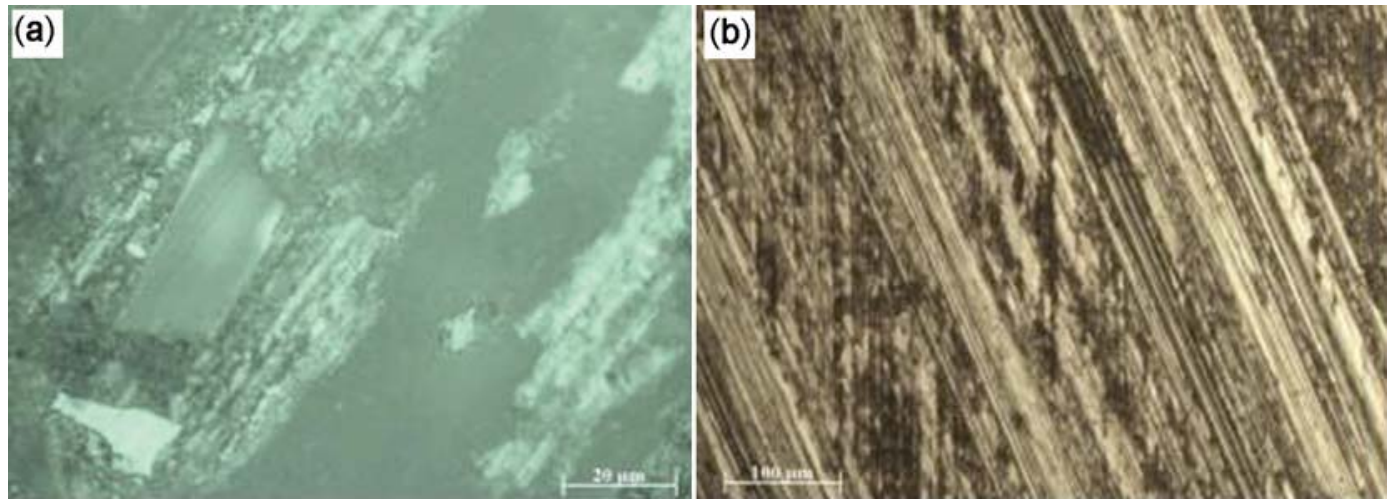

Figure 13. (a) Optical microscopy of pin surface of PTFE $+35 \%$ GF after wear test at $P=45 \cdot 1 \mathrm{~N}$ and $V=2 \mathrm{~m} / \mathrm{s}(500 \times)$; and (b) optical microscopy of disc surface of EN 8 after wear test.

Table 4. Results of regression analysis for oil lubrication condition.

\begin{tabular}{llc}
\hline Set no & Mathematical model & Regression coefficient \\
\hline 1 & $W=4.1781 \times P^{0.2054} \times V^{0.1584} \times G^{-0.2271}$ & $R^{2}=0.958$ \\
2 & $W=1.6556 \times P^{-0.4727} \times V^{0.2149} \times G^{-0.4166}$ & $R^{2}=0.956$ \\
3 & $W=3.1519 \times P^{0.6780} \times V^{0.3732} \times G^{-0.6436}$ & $R^{2}=0.923$ \\
\hline
\end{tabular}

Table 5. Results of regression analysis for oil $+5 \%$ graphite condition.

\begin{tabular}{lcc}
\hline Set no & Mathematical model & Regression coefficient \\
\hline 1 & $W=3.4398 \times P^{0.3389} \times V^{-0.1311} \times G^{-0.4871}$ & $R^{2}=0.999$ \\
2 & $W=4.5091 \times P^{0.2867} \times V^{-0.1288} \times G^{-0.4477}$ & $R^{2}=0.792$ \\
3 & $W=2.1383 \times P^{0.05209} \times V^{-0.2547} \times G^{-0.9349}$ & $R^{2}=0.580$ \\
\hline
\end{tabular}

Table 6. Levels in coded form

\begin{tabular}{lccl}
\hline & \multicolumn{3}{c}{ Level in coded form } \\
\cline { 2 - 4 } Parameters & -1 (low) & 0 (centre) & 1 (high) \\
\hline Pressure $P(\mathrm{MPa})$ & 0.2 & 0.325 & 0.45 \\
Sliding velocity $V(\mathrm{~m} / \mathrm{s})$ & 0.5 & 1 & 2 \\
Glass fibre G $(\%)$ & 0.15 & 0.25 & 0.35 \\
\hline
\end{tabular}

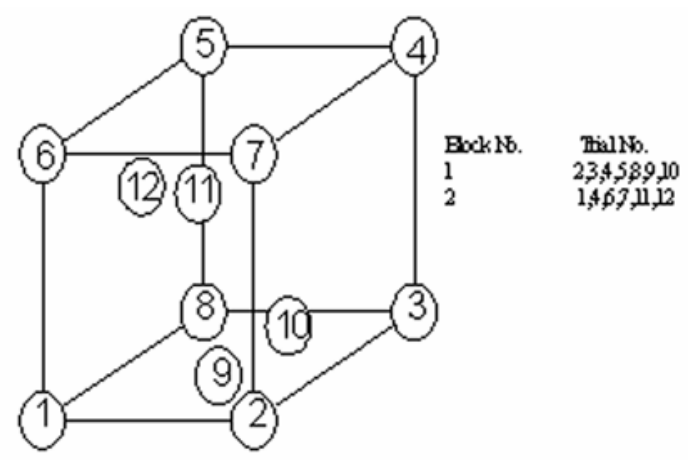

Figure 14. Composite design. values were determined by using MINITAB 14 software.

The equation with higher value of regression coefficient can be selected as the best model. So, equation 1, both from tables 4 and 5 are considered as the best model equation. Model equations are found to be in good agreement with the experimental values.

\section{Conclusions}

For the PTFE with GF composites, initially wear is more, and after certain sliding distance wear curve shows very small change in wear. This may be due to formation of more and more uniform transfer film on the counterface with increase in sliding distance. Frictional coefficient initially increases with sliding time and later on it remains almost constant. Wear increases with increase in applied load. Specific wear rate remains almost constant with increase in load (material 15\% GF and $25 \%$ GF) and for material $35 \% \mathrm{GF}$ specific wear rate decreases with increase in load. For oil and oil with graphite lubrication condition for all material-specific wear rate decreases with increase in load. The value of coefficient of friction 
is very less in oil and oil with graphite lubrication. The range of coefficient of friction in oil and graphite lubrication condition is about 0.015-0.09 for given load and speed which is about $1 / 10$ th as compared to dry condition. There is very little effect of sliding speed on wear of the PTFE + GF composites. The value of coefficient of friction almost remains constant or lightly decreases with increase in sliding speeds. Specific wear rate decreases with increase in sliding speed for all lubricating conditions. The range of specific wear rate for material PTFE $+15 \%$ GF is $2 \times 10^{-6}$ to $9 \times 10^{-6} \mathrm{~mm}^{3} / \mathrm{Nm}$; for $\mathrm{PTFE}+25 \%$ GF is $2.5 \times 10^{-6}$ to $9 \times 10^{-6} \mathrm{~mm}^{3} / \mathrm{Nm}$ and for PTFE $+35 \%$ GF is $1 \times 10^{-6}$ to $4 \times 10^{-6} \mathrm{~mm}^{3} / \mathrm{Nm}$ in oil lubrication condition. Hence the material PTFE $+35 \%$ GF has least specific wear rate and PTFE $+25 \%$ GF has highest specific wear rate. The range of specific wear rate for material PTFE $+15 \% \mathrm{GF}$ is $2.6 \times 10^{-6}$ to $1.2 \times 10^{-5}$ $\mathrm{mm}^{3} / \mathrm{Nm}$; for PTFE $+25 \% \mathrm{GF}$ is $2 \times 10^{-6}$ to $2.7 \times 10^{-6}$ $\mathrm{mm}^{3} / \mathrm{Nm}$ and for PTFE $+35 \%$ GF is $1 \times 10^{-6}$ to $2.6 \times 10^{-6}$ $\mathrm{mm}^{3} / \mathrm{Nm}$ in oil $+5 \%$ graphite lubrication condition. Hence the material PTFE $+35 \%$ GF has least specific wear rate and PTFE $+25 \%$ GF has highest specific wear rate. Specific wear rate of material PTFE $+35 \%$ GF is less than the PTFE $+25 \% \mathrm{GF}$ and PTFE $+15 \% \mathrm{GF}$ in all conditions; therefore material $35 \% \mathrm{GF}$ is better than the material $25 \% \mathrm{GF}$ and $15 \% \mathrm{GF}$, i.e. wear resisting capacity of PTFE base composites increases with increase in percentage of glass fibres. The value of specific wear rate is least in oil with graphite lubrication (except for material $15 \% \mathrm{GF}$ ). Optical microscopic analysis of few pin samples and counterpart in wet condition has been made and it is found that a very thin microlayer film gets formed on the counter surface. Also microscopy shows broken glass fibres on the pin surface after the wear test. Experimental results are also compared with mathematical model and it is found that they are in good agreement with the experimental values. In general, wear resistance of PTFE increases with glass fibre fillers and composites have good friction and wear behaviour at higher speeds, so it can be more effectively used for high speed applications. Also the wear of the PTFE composites can be decreased by using oil and oil with graphite lubrication.

\section{References}

Briscoe B J and Tabor D 1980 Tribology 733

Baiming Chen, Qinling Bi, Jun Yang, Yanqiu Xia and Jingcheng Hao 2008 Tribol. Int. 38824

Bin-Bin Jia, Tong-Sheng Li, Xu-Jun Liu and Pei-Hong Cong 2007 Wear 2621353

Bressana J D, Darosa D P and Barbosad C A 2008 J. Mater. Process. Technol. 205353

Erol Feyzullahoglu and Zehra Saffak 2008 Mater. \& Design 29 205

Feng-hua Sua, Zhao-zhu Zhang and Wei-min Liu 2008 Wear 265311

Gregory S W, Freudenberg K D, Bhimaraj P and Schadler L S 2003 Wear 254573

Klaasa N V, Marcusa K and Kellock C 2005 Tribol. Inter. 38 824

Klaus Friedrich, Zhong Zhang and Alois K Schlarb 2005 Compos. Sci. \& Technol. 6523

Kowandya C, Richarda C and Chenb Y M 2008 Wear 2641152

Lancaster J K 1968 J. Phys. DI 549

Shirsat U M and Ahuja B B 2005 IE (I) J. MC 86

Shyam Bahadur 2000 Wear 24592

Theiler G, .Hubner W and Friedrich K 2002 Tribol. Int. 35449

Unal H, Mimaroglu A, Kadýoglu U and Ekiz H 2004 Mater. \& Design 25239

Unal H, Sen U and Mimaroglu A 2006 Mater. \& Design 27 694

Wu Y Y, Tsui W C and Liu T C 2007 Wear 262819

Yuji Yamamoto and Masaaki Hashimoto 2004 Wear 257181

Yunxia Wang and Fengyuan Yan 2006 Wear 2611359

Zhao-Zhu Zhang, Qun-Ji Xue, Wei-Min Liu and Wei-Chang Shen 1997 Wear 210151 